\title{
Estimation of area function from 3-D magnetic resonance images of vocal tract using finite element method
}

\author{
Keita Mochizuki and Takayoshi Nakai* \\ The Graduate School of Electronic Science and Technology, Shizuoka University, \\ 3-5-1 Johoku, Hamamatsu, 432-8561 Japan
}

(Received 15 December 2006, Accepted for publication 12 March 2007)

Keywords: Vocal tract area function, Finite element method, MRI, Pressure contour PACS number: 43.70.Bk [doi:10.1250/ast.28.346]

\section{Introduction}

The purpose of the study is to develop a method for estimating the area function from 3-D magnetic resonance (MR) images of the vocal tract. To obtain the area function from a 3-D vocal tract image, the vocal tract is usually divided by flat planes. However, this division is difficult because the shape of the vocal tract is curved. Therefore, we used pressure contours instead of flat planes to estimate the area function. To calculate the acoustic characteristics from the vocal tract image, we used the finite element method (FEM). We calculated the area function from acoustical parameters obtained using FEM.

\section{Procedure}

We used sagittal MR images of the vocal tract of two adult male subjects (A and B) uttering five Japanese vowels: /a/, /i/, /u/, /e/, and /o/. We extracted the vocal tracts without the nasal cavities from the images by hand.

We used a solver application of FEM (LMS SYSNOISE ver. 5.5) for obtaining acoustical parameters. The density of air was $1.14 \mathrm{~kg} / \mathrm{m}^{3}$, and its sound velocity was $353 \mathrm{~m} / \mathrm{s}$. The boundary condition of input was a constant particle velocity of $1.0 \mathrm{~m} / \mathrm{s}$. The boundary condition of output was approximated as the radiation admittance of a circular piston in an infinitely flat baffle [1]. The other boundary was a rigid wall. Each element was cubic. The size of the cubic elements was $1.5 \times 1.5 \times 1.5 \mathrm{~mm}^{3}$. We calculated the first, second and third formant frequencies $\left(F_{1}, F_{2}\right.$, and $F_{3}$, respectively), and the sound pressure and sound intensity in the vocal tract at $F_{1}$ to calculate the area function; because it is shown that the wave front is almost one-dimensional in the frequency region up to about $4 \mathrm{kHz}$ [2], it is considered that the shape of the wave front at $F_{1}$ is a gradually curving surface.

It is necessary to divide the vocal tract into a number of sections to estimate the area function. We employed pressure contours to section the vocal tract. The pressure contours were detected along the centerline, which was obtained using a thinning algorithm. To determine section length, we calculated the thickness of the subsections [3]. The subsection was a region surrounded by two neighboring pressure contours and the wall of the vocal tract, and the section was an assembly of several adjacent subsections. We determined the thickness of the subsections using the sound flow in each element

\footnotetext{
*e-mail: tdtnaka@ipc.shizuoka.ac.jp
}

included in the boundary of the subsection. The sound flow is represented by the real part of sound intensity (Fig. 1(a)). For the proposed method, sound needs to propagate as a plane wave. The amplitude of sound pressure has a local maximum and a local minimum at $F_{2}$ and $F_{3}$, respectively (Figs. 1(b) and 1(c)). In these places, even though the directions of sound flow are typical, the shape of the pressure contour is likely to be circular or semicircular instead of zonal (Fig. 1(d)). Therefore, we used only pressure contours at $F_{1}$. The length of the vocal tract was defined as the sum of the subsection thicknesses. The area functions were calculated using section length and section volume. Then, the frequency response of the area function was calculated by constructing a loss-less acoustically equivalent circuit consisting of inductors and capacitors.

For a comparison with the proposed method, we employed a conventional method using planes for cross-sections, and estimated the area function. The conventional method used divides the vocal tract with flat planes. The angle and position of the planes were determined with respect to the centerline.

\section{Results and discussion}

Figure 2 shows examples of the divisions of the vocal tract and the area functions derived by two methods. The area functions derived by the two methods have similar shapes. Table 1 shows the values of $F_{1}, F_{2}$ and $F_{3}$ obtained using FEM, the proposed method, and the conventional method. In the proposed method, the absolute values of the relative errors were less than $2 \%$ in all the cases at $F_{1}$ and in almost all the cases at $F_{2}$ and $F_{3}$. When the errors of the two methods were compared, those of the proposed method were smaller except for the $F_{1} \mathrm{~s}$ of $/ \mathrm{i} / \mathrm{B}$ and $/ \mathrm{e} / \mathrm{B}$, and the $F_{3} \mathrm{~s}$ of $/ \mathrm{u} / \mathrm{A}, / \mathrm{o} / \mathrm{A}, / \mathrm{i} / \mathrm{B}$, $/ \mathrm{e} / \mathrm{B}$, and $/ \mathrm{o} / \mathrm{B}$. Concerning the average of the absolute value of errors, that of the proposed method was significantly smaller: that of the proposed method was $1.59 \%$ and that of the conventional method was $3.95 \% \quad(t(29)=-4.57$, $p<0.001)$. Therefore, the proposed method is a better algorithm than the conventional one.

\section{Conclusions}

The development of a method for the precise estimation of the area function, and the application of such method to 3D MR images from two adult males by using sound pressure contours derived using FEM are shown. The area function can 


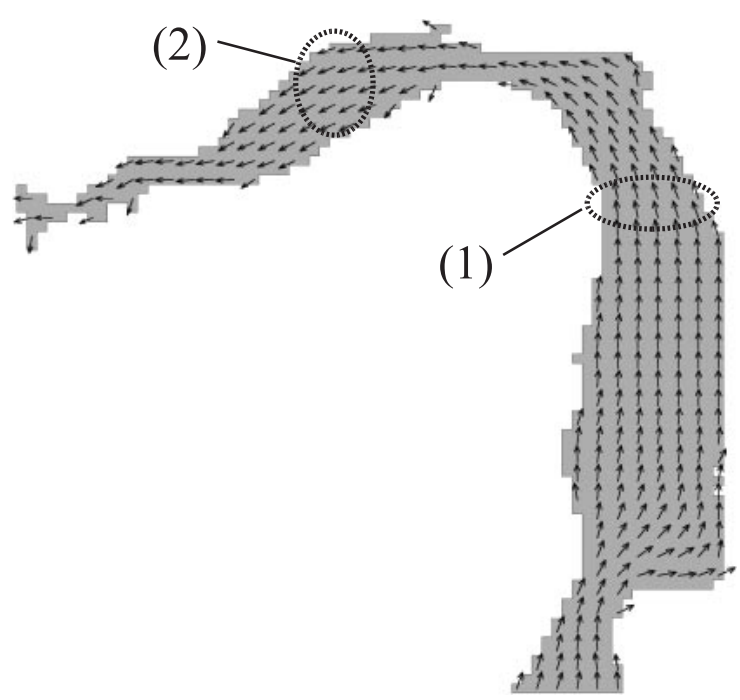

(a) sound flow

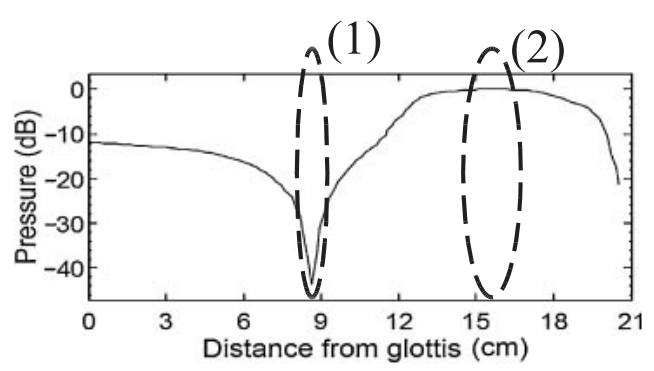

(c) relative pressure on centerline

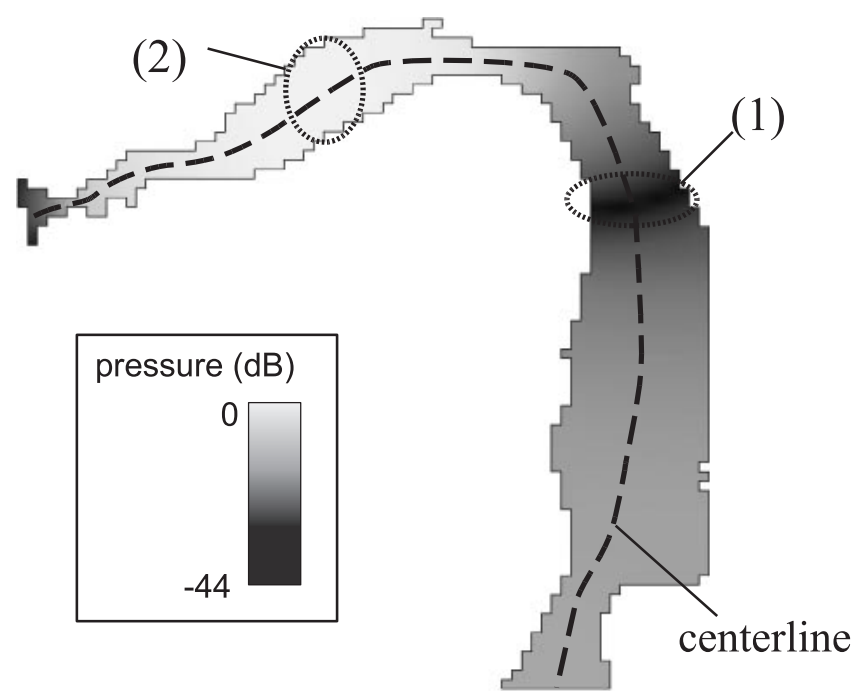

(b) pressure distribution

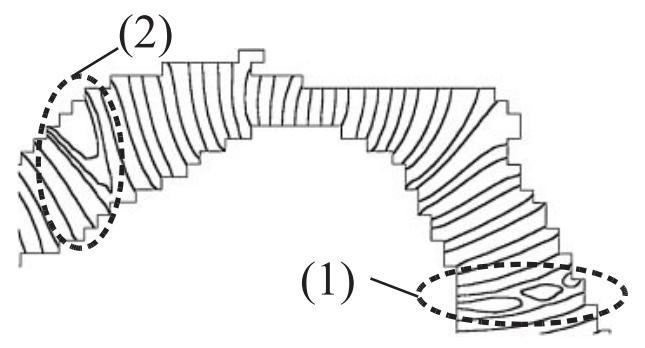

(d) pressure contours

Fig. 1 Example of sound flow, pressure distribution and pressure contours on midsagittal plane at $F_{2}$ of $/ \mathrm{u} / \mathrm{uttered}$ by subject A. The sound flow is shown in (a). In (b) and (c), there is a local minimum (at (1)) and a local maximum (at (2)). There are three circular contours at (1), two semicircular contours at (2), and zonal contours at others in (d).

be estimated more precisely using the proposed method than using the conventional method, particularly at $F_{1}$. Because the proposed method enables the determination of the position of articulation of the vocal tract from the area function more accurately, a future work will be to observe the motion of articulation.

\section{Acknowledgments}

We wish to acknowledge Dr. S. Masaki and Dr. K. Honda of ATR (Kyoto, Japan) for allowing us to use their 3-D MR images. The MRI data used in this study is part of "ATR MRI data of Japanese vowel production" that were acquired at and released from ATR Human Information Science Laboratories under "Research on Human Communication" funded by the
National Institute of Information and Communications Technology. The use of the database and release of the results are under the license agreement with ATR.

\section{References}

[1] C. X. Lu, T. Nakai and H. Suzuki, "A numerical simulation of the effects of the actual lip geometry on acoustic fields by a three-dimensional FEM," IEICE Trans., E77-A, 422-428 (1994).

[2] K. Motoki, N. Miki and N. Nagai, "Measurement of soundpressure distribution in replicas of the oral cavity," J. Acoust. Soc. Am., 92, 2577-2585 (1992).

[3] K. Mochizuki and T. Nakai, "Estimation of the vocal tract area function for three-dimensional model using finite element method," IEICE Tech. Rep., SP2006-22, pp. 11-14 (2006). 


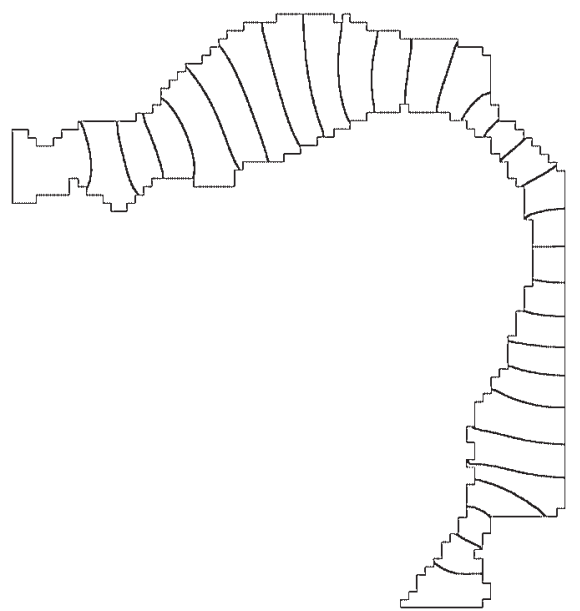

(a) proposed method

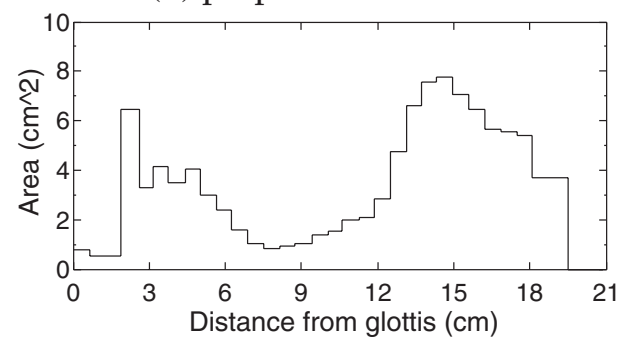

(c) proposed method

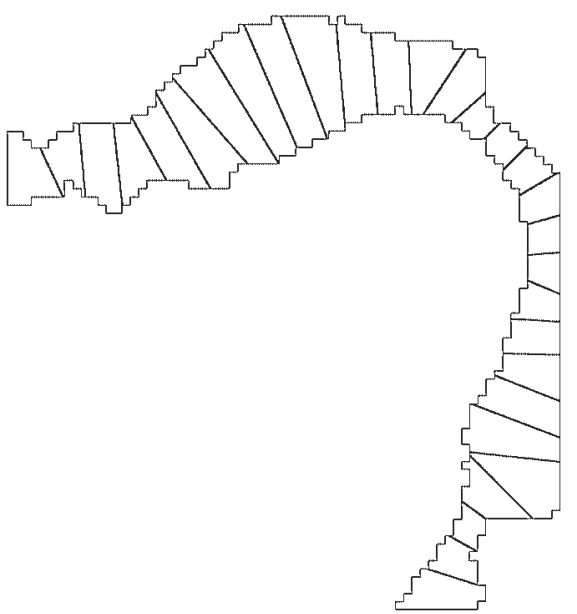

(b) conventional method

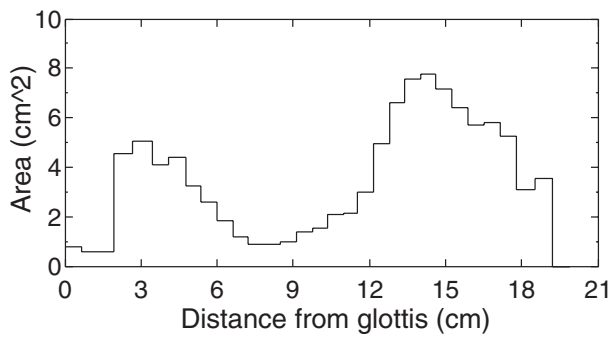

(d) conventional method

Fig. 2 (a)(b): section boundaries on midsagittal plane derived by two methods. The number of sections is 30. (c)(d): examples of area functions for $/ \mathrm{a} /$ of subject $\mathrm{A}$. The horizontal-axis records the path length from the glottis to the lips.

Table 1 Comparison of values of $F_{1}, F_{2}$, and $F_{3}$ obtained by FEM, proposed method, and conventional method. The relative error rate was defined as $\left(F_{\mathrm{a}}-F_{\mathrm{f}}\right) / F_{\mathrm{f}}$, where $F_{\mathrm{f}}$ is the frequency obtained by FEM and $F_{\mathrm{a}}$ is the frequency from the proposed and conventional methods. /a/A indicates that /a/ was uttered by subject $\mathrm{A}, / \mathrm{a} / \mathrm{B}$ indicates that /a/ was uttered by subject $\mathrm{B}$, and the others are indicated in the same fashion.

\begin{tabular}{|c|c|c|c|c|c|c|c|c|c|c|c|c|c|c|c|}
\hline \multirow{3}{*}{ Vowel } & \multicolumn{5}{|c|}{$F_{1}$} & \multicolumn{5}{|c|}{$F_{2}$} & \multicolumn{5}{|c|}{$F_{3}$} \\
\hline & \multirow{2}{*}{$\begin{array}{c}\text { FEM } \\
\text { Freq. } \\
{[\mathrm{Hz}]}\end{array}$} & \multicolumn{2}{|c|}{$\begin{array}{l}\text { Proposed } \\
\text { method }\end{array}$} & \multicolumn{2}{|c|}{$\begin{array}{l}\text { Conventional } \\
\text { method }\end{array}$} & \multirow{2}{*}{$\begin{array}{c}\text { FEM } \\
\text { Freq. } \\
{[\mathrm{Hz}]}\end{array}$} & \multicolumn{2}{|c|}{$\begin{array}{l}\text { Proposed } \\
\text { method }\end{array}$} & \multicolumn{2}{|c|}{$\begin{array}{l}\text { Conventional } \\
\text { method }\end{array}$} & \multirow{2}{*}{$\begin{array}{c}\text { FEM } \\
\text { Freq. } \\
{[\mathrm{Hz}]}\end{array}$} & \multicolumn{2}{|c|}{$\begin{array}{l}\text { Proposed } \\
\text { method }\end{array}$} & \multicolumn{2}{|c|}{$\begin{array}{l}\text { Conventional } \\
\text { method }\end{array}$} \\
\hline & & $\begin{array}{l}\text { Freq. } \\
{[\mathrm{Hz}]}\end{array}$ & $\begin{array}{c}\text { Error } \\
{[\%]}\end{array}$ & $\begin{array}{l}\text { Freq. } \\
{[\mathrm{Hz}]}\end{array}$ & $\begin{array}{c}\text { Error } \\
{[\%]}\end{array}$ & & $\begin{array}{l}\text { Freq. } \\
{[\mathrm{Hz}]}\end{array}$ & $\begin{array}{c}\text { Error } \\
{[\%]}\end{array}$ & $\begin{array}{l}\text { Freq. } \\
{[\mathrm{Hz}]}\end{array}$ & $\begin{array}{c}\text { Error } \\
{[\%]}\end{array}$ & & $\begin{array}{l}\text { Freq. } \\
{[\mathrm{Hz}]}\end{array}$ & $\begin{array}{c}\text { Error } \\
{[\%]}\end{array}$ & $\begin{array}{l}\text { Freq. } \\
{[\mathrm{Hz}]}\end{array}$ & $\begin{array}{c}\text { Error } \\
{[\%]}\end{array}$ \\
\hline$/ \mathrm{a} / \mathrm{A}$ & 463 & 460 & -0.65 & 459 & -0.86 & 1,075 & 1,035 & -3.72 & 1,007 & -6.35 & 2,655 & 2,666 & 0.41 & 2,720 & 2.45 \\
\hline$/ \mathrm{i} / \mathrm{A}$ & 180 & 182 & 1.1 & 186 & 3.33 & 2,068 & 2,056 & -0.58 & 2,100 & 1.55 & 2,999 & 2,897 & -3.4 & 2,660 & -11.3 \\
\hline$/ \mathrm{u} / \mathrm{A}$ & 239 & 238 & -0.42 & 255 & 6.69 & 1,092 & 1,093 & 0.09 & 1,158 & 6.04 & 2,266 & 2,301 & 1.54 & 2,297 & 1.37 \\
\hline$/ \mathrm{e} / \mathrm{A}$ & 387 & 391 & 1.03 & 401 & 3.62 & 1,650 & 1,678 & 1.7 & 1,713 & 3.82 & 2,406 & 2,427 & 0.87 & 2,469 & 2.62 \\
\hline$/ \mathrm{o} / \mathrm{A}$ & 319 & 320 & 0.31 & 337 & 5.64 & 698 & 699 & 0.14 & 760 & 8.88 & 2,476 & 2,520 & 1.78 & 2,505 & 1.17 \\
\hline$/ \mathrm{a} / \mathrm{B}$ & 599 & 608 & 1.5 & 608 & 1.5 & 1,158 & 1,167 & 0.78 & 1,176 & 1.55 & 2,290 & 2,331 & 1.79 & 2,355 & 2.84 \\
\hline$/ \mathrm{i} / \mathrm{B}$ & 204 & 206 & 0.98 & 203 & 0.49 & 1,919 & 1,930 & 0.57 & 2,053 & 6.98 & 2,750 & 2,806 & 2.04 & 2,753 & 0.11 \\
\hline$/ \mathrm{u} / \mathrm{B}$ & 280 & 280 & 0 & 268 & -4.29 & 1,168 & 1,174 & 0.51 & 1,145 & -1.97 & 2,007 & 2,127 & 5.98 & 2,197 & 9.46 \\
\hline$/ \mathrm{e} / \mathrm{в}$ & 412 & 410 & -0.49 & 413 & 0.24 & 1,521 & 1,573 & 3.42 & 1,580 & 3.88 & 2,008 & 2,132 & 6.18 & 2,114 & 5.28 \\
\hline$/ \mathrm{o} / \mathrm{B}$ & 429 & 437 & 1.86 & 460 & 7.23 & 834 & 851 & 2.04 & 884 & 6.00 & 2,313 & 2,352 & 1.69 & 2,334 & 0.91 \\
\hline
\end{tabular}

